\title{
Usefulness of Valsalva manoeuvre and cold pressor test for evaluation of arrhythmias in long QT syndrome ${ }^{1}$
}

\author{
STANLEY A. RUBIN, BRUCE BRUNDAGE, WILLIAM MAYER, AND KANU \\ CHATTERJEE
}

From the Department of Medicine, Cardiovascular Division, and the Cardiovascular Research Institute, University of California, San Francisco, California; and the Department of Medicine, Division of Cardiology, The Alaska Hospital and Medical Center, Anchorage, Alaska, USA

SUMMARY Ventricular arrhythmias were precipitated with reflex testing in a case of the long QT syndrome and were abolished after acute administration of propranolol.

Since the original description of a hereditary syndrome of prolongation of the electrocardiographic QT interval, syncope and sudden death, with congenital deafness (Jervell and Lange-Nielsen, 1957) or with normal hearing (Romano et al., 1963; Ward, 1964), clinical evidence has accumulated to implicate the autonomic nervous system in the genesis of arrhythmia. The effects of catecholamine infusion (Garza et al., 1970; Mathews et al., 1972) and exercise (Roy et al., 1976) have been reported to cause ventricular tachycardia and fibrillation in this syndrome. We tested the hypothesis that reflex manoeuvres would precipitate arrhythmias and found such testing useful for assessing the efficacy of antiarrhythmic therapy.

\section{Case report}

A 23-year-old white woman was referred to the University of California, San Francisco, for evaluation of recent postoperative arrhythmias. The patient was the product of a normal conception and delivery. During childhood she suffered 3 seizures and was treated with diphenylhydantoin until adolescence. She remained well until syncopal episodes occurred without warning during pregnancy: 1 episode during her first pregnancy and 2 during her second. For the past year she had been healthy, but was recently admitted to Alaska Hospital for minor pelvic surgery. Postoperatively she was noted to have frequent premature ventricular

\footnotetext{
${ }^{1}$ This work was supported in part by an NHLBI Program
} Project Grant. contractions, a potassium of $2.8 \mathrm{mmol} / 1$, and a magnesium of $1.6 \mathrm{mmol} / 1$. Potassium correction was undertaken and the patient transferred to the coronary care unit for monitoring. After transfer, short runs of ventricular tachycardia were noted. Treatment with bolus and infusion of lignocaine and procainamide was begun, together with an oral dose of quinidine. Runs of ventricular tachycardia occurred, followed by ventricular fibrillation. Cardiopulmonary resuscitation and praecordial electric shock restored normal rhythm. An electrocardiogram taken before cardiac arrest showed a QT interval of 0.46 second with a heart rate of 77 . The calculated corrected QT (QTc) (Bazett, 1920) was prolonged to 0.52 second, with the upper limit of normal 0.425 second (Massie and Walsh, 1960). After treatment with bolus propranolol and supplemental potassium, the QT was 0.44 second at a heart rate of 71 (QTc $=0.48)$. There was an uneventful recovery. On the day of discharge, while on propranolol, $120 \mathrm{mg}$, and diphenylhydantoin, $300 \mathrm{mg}$, orally per day, she underwent progressive treadmill exercise with premature ventricular contractions at rest, which were abolished with exercise. Her dose of propranolol was subsequently increased to $160 \mathrm{mg}$ per day. An audiogram was normal.

On admission she was a well-developed, wellnourished young woman in no acute distress. Vital signs, physical examination, and chest $x$-ray film were normal. Laboratory blood electrolyte values included a potassium of $4.0 \mathrm{mmol} / 1$ and a magnesium of $2.3 \mathrm{mmol} / 1$. The electrocardiogram was normal, except for a QT of 0.48 second, with a heart rate of $55(\mathrm{QTc}=0.46)$ at a time when the propranolol level was $200 \mathrm{ng} / \mathrm{ml}$ and the diphenyl- 


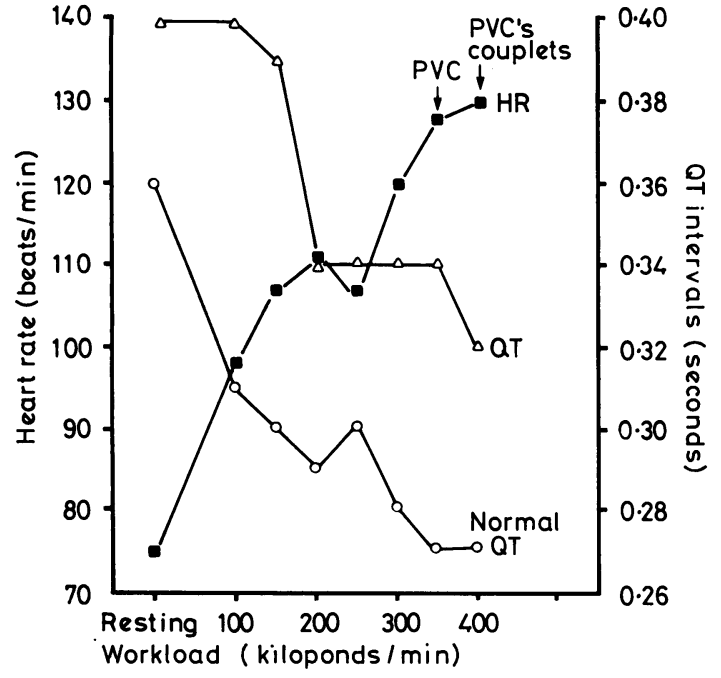

Fig. 1 Heart rate and $Q T$ during exercise. Heart rate (solid squares) increased during exercise and was associated with premature ventricular contractions $(P V C) . Q T$ interval (open triangles) was prolonged at rest and at exercise, compared with the upper limit of normal for $Q T$ corrected for heart rate (open circles).

hydantoin level was $5 \mu \mathrm{g} / \mathrm{ml}$. Her mother had been admitted to hospital for syncopal episodes with a reportedly normal QT interval; a brother had an electrocardiogram which showed right bundlebranch block; and a nephew had congenital unilateral deafness and motor difficulty.

\section{HOSPITAL STUDIES}

\section{Exercise}

All drugs, including antiarrhythmics, were stopped at least 24 hours before any studies. No arrhythmias were observed with the patient at rest during continuous monitoring.

In the cardiac catheterisation laboratory the patient underwent progressive supine bicycle exercise. The QT interval, which was prolonged at rest, showed progressive shortening with exercise, but nevertheless remained prolonged above normal (Fig. 1). At 400 kiloponds/min ventricular ectopy was manifested with coupled beats. Cardiac metabolism at rest and with exercise was normal, as judged from positive lactate extraction between coronary sinus and arterial blood.

\section{Reflexes}

The cold pressor test was performed with the hand immersed in ice water at $1^{\circ} \mathrm{C}$. After 1 minute of immersion, ventricular bigeminy developed (Fig. 2). During Valsalva manoeuvre blowing, heart rate increased. With release, ventricular bigeminy occurred (Fig. 3). These studies were repeated after a $6 \mathrm{mg}$ intravenous dose of propranolol. Heart rate response was diminished and no arrhythmias were observed. Each reflex manoeuvre was performed twice, both before and after propranolol. The results were the same each time.

In the past 6 months of outpatient follow-up, the patient has remained symptom and arrhythmia free on propranolol, $160 \mathrm{mg} /$ day in divided doses.

\section{Discussion}

This case represents a potpourri of clinical features previously reported separately in the long QT interval syndrome. The early childhood 'seizures' were providentially treated with diphenylhydantoin, a drug said to shorten ventricular repolarisation (Bigger et al., 1968). Further delay of syncopal episodes until young adult life is consistent with the previously reported onset of clinical manifestations

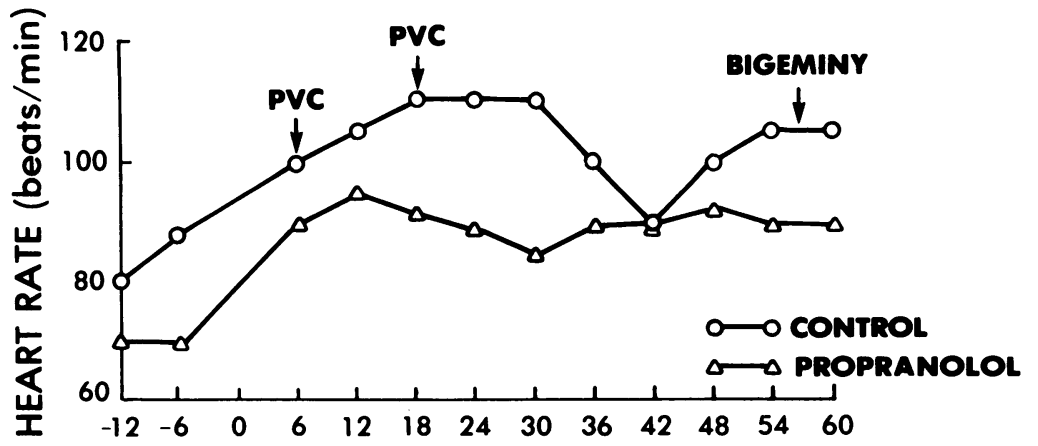

Fig. 2 Cold pressor test. After hand immersion in ice water, premature ventricular contractions and ventricular bigeminy were noted. With beta-blockade, the increment of increase in heart rate was similar, but no ectopy occurred.

TIME FROM HAND IMMERSION, SECONDS 


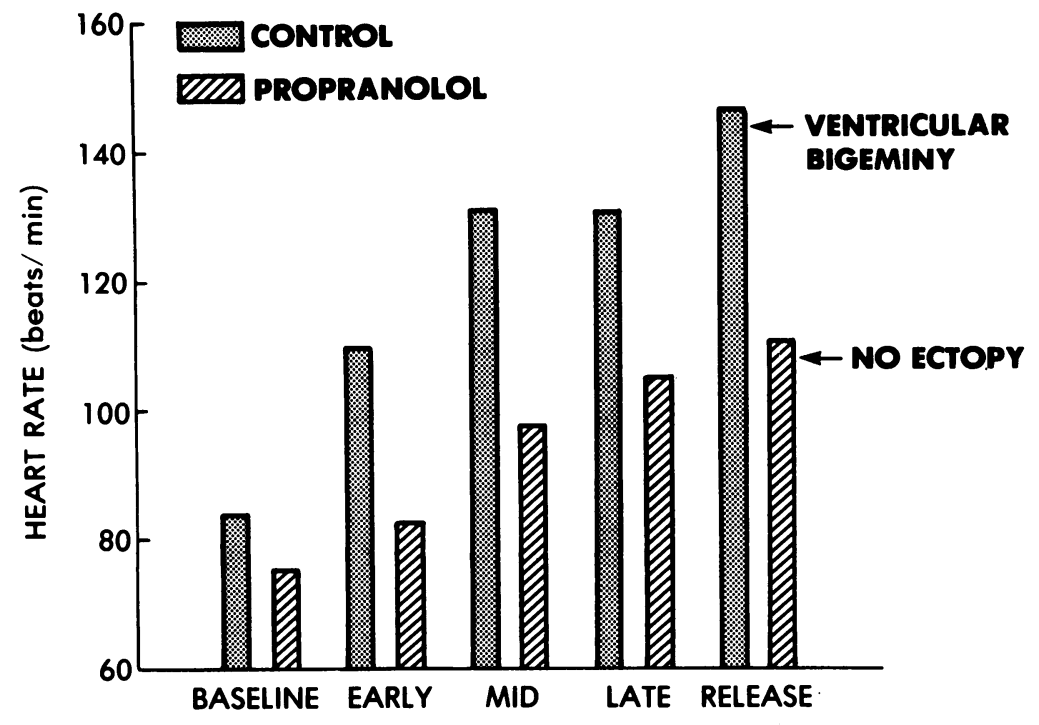

Fig. 3 Valsalva manoeuvre. Heart rate rose during Valsalva manoeuvre and with release ventricular bigeminy occurred. After beta-blockade, repeat manoeuvre caused no ectopy. with variable age (Garza et al., 1970; Mathews et al., 1972; Roy et al., 1976). The occurrence of severe arrhythmic episodes while in hospital for surgery may, in part, be attributed to stress in the postoperative period, as well as metabolic derangement. A single dose of quinidine was also administered and may have contributed to ventricular vulnerability (DiPalma and Shults, 1950).

The clinical evidence for a role of the sympathetic nervous system in the long QT syndrome includes precipitation of arrhythmias with exercise, emotional excitement, and catecholamine infusion and abolition of arrhythmias with beta-blockade (Jervell and Sivertssen, 1967; Garza et al., 1970; Schwartz et al., 1975; Roy et al., 1976). After stellate ganglion blockade or left sympathectomy, shortening of the QT interval has been invoked as evidence for a disparity between sides of the stellate ganglion in sympathetic nervous system outflow to the ventricle (Schwartz et al., 1975). In our patient, precipitation of ventricular arrhythmia with the Valsalva manoeuvre and a cold pressor test, and abolition of arrhythmia with propranolol, also provide examples of the precipitation of arrhythmias in the long QT syndrome by an action on the sympathetic chain. Our observation that propranolol abolished the ventricular arrhythmias associated with reflex manoeuvres and exercise is in agreement with the beta-blocking effect of this drug and at variance with the suggested direct antiarrhythmic effect (Garza et al., 1970).

Although a recent review of drug therapy suggests the superiority of propranolol (Schwartz et al., 1975), we encourage an individual approach in this serious malady. Using electrocardiographic monitoring, simple exercise testing and reflex manoeuvres may be useful to uncover ventricular ectopy and to assess drug therapy.

\section{References}

Bazett, H. C. (1920). An analysis of the time relation of electrocardiograms. Heart, 7, 353-370.

Bigger, J. T., Jr., Bassett, A. L., and Hoffman, B. F. (1968). Electrophysiological effects of diphenylhydantoin on canine Purkinje fibers. Circulation Research, 22, 221-236.

DiPalma, J. R., and Shults, J. E. (1950). Antifibrillatory drugs. Medicine, 29, 123-168.

Garza, L., Vick, R., Nora, J. J., and McNamara, D. G. (1970). Heritable Q-T prolongation without deafness. Circulation, 41, 39-48.

Jervell, A., and Lange-Nielsen, F. (1957). Congenital deaf mutism, functional heart disease with prolongation of the QT interval and sudden death. American Heart fournal, 54, 59-68.

Jervell, A., and Sivertssen, E. (1967). Surdo-cardiac syndrome. Nordisk Medicin, 78, 1443-1450.

Massie, E., and Walsh, T. (1960). Clinical Electrocardiography and Vectorcardiography. Year Book Publishers, Chicago.

Mathews, E. C., Jr., Blount, A. W., Jr., and Townsend, J. I. (1972). Q-T prolongation and ventricular arrhythmias, with and without deafness, in the same family. American Fournal of Cardiology, 29, 702-711.

Romano, C., Gemme, G., and Pongiglione, R. (1963). Aritimie cardiache rare dell'eta pediatrica. Clinica Pediatrica, 45, 656-683.

Roy, P. R., Emanuel, R., Ismail, S. A., and El Tayib, M. H. (1976). Hereditary prolongation of the Q-T interval. American fournal of Cardiology, 37, 237-243.

Schwartz, P. J., Periti, M., and Malliani, A. (1975). The long Q-T syndrome. American Heart fournal, 89, 378-390.

Ward, O. C. (1964). A new familial cardiac syndrome in children. Fournal of the Irish Medical Association, 54, 103106.

Requests for reprints to Dr Stanley A. Rubin, Cardiovascular Division, Room 1186-Moffitt Hospital, University of California, San Francisco, California 94143, USA. 